\title{
Akses Karya Cipta Audiobook Bagi Disabilitas Netra : Perspektif HAM
}

\author{
Bagus Gede Ari Rama1, Ni Ketut Supasti Dharmawan² \\ ${ }^{1}$ Program Studi Magister (S2) Ilmu Hukum Universitas Udayana, \\ E-mail : bemz.recht@gmail.com \\ ${ }^{2}$ Fakultas Hukum Universitas Udayana, E-Mail : arasswk@yahoo.com
}

\begin{tabular}{l}
\hline Info Artikel \\
\hline Masuk : 21 Nopember 2019 \\
Diterima : 02 Desember 2019 \\
Terbit : 31 Desember 2019 \\
Keywords : \\
Access, Copyright, Disability, \\
Human Rights \\
\\
Kata kunci: \\
Akses, Karya Cipta, Disabilitas, \\
Hak Asasi Manusia \\
Corresponding Author: \\
Bagus Gede Ari Rama, \\
E-mail: bemz.rech@gmail.com \\
DOI : \\
10.24843/AC.2019.v04.i03.p08 \\
\end{tabular}

\begin{abstract}
Audiobook access for people with disabilities is very important. Access is the convenience that people get from a service. This study aims to analyze the legal certainty and legal protection of audiobook copyright access for blind people with disabilities. This study uses a normative legal research method with a statutory approach and comparative approach. This research found that access to audiobooks' works has been regulated in the Marrakech Treaty, Copyright Act Number 28 of 2014 and Government Regulation Number 27 of 2019.
\end{abstract}

\begin{abstract}
Abstrak
Akses karya cipta audiobook bagi disabilitas sangat penting. Aksesibilitas merupakan kemudahan yang didapat oleh orang terhadap suatu layanan. Penelitian ini bertujuan untuk menganalisis kepastian hukum serta perlindungan hukum akses karya cipta audiobook bagi disabilitas tuna netra. Penelitian ini menggunakan metode penelitian hukum normatif dengan pendekatan perundangundangan dan pendekatan komparatif. Dalam penelitian ini menemukan bahwa akses karya cipta audiobook telah diatur dalam Traktat Marrakesh, UUHC 2014 serta Peraturan Pemerintah Nomor 27 Tahun 2019.
\end{abstract}

\section{Pendahuluan}

Kaum difabel sudah sepantasnya mendapatkan perlakuan yang setara, terlebih dalam bidang hukum, kaum difabel harus diperlakukan setara di hadapan hukum.

Kaum difabel di seluruh dunia diperkirakan berjumlah 600 juta jiwa, masyarakat mulai mengkritisi isu perlindungan HAM bagi kaum difabel melalui sebuah pergerakan pada tahun 1982, pada saat itu seluruh negara berkomitmen untuk menghapuskan tindakan diskriminatif bagi kaum difabel. ${ }^{1}$

\footnotetext{
${ }^{1}$ Dewi, A. A. I. A. A. (2018). Aspek Yuridis Perlindungan Hukum dan Pemenuhan Hak Penyandang Disabilitas. Pandecta: Research Law Journal, 13(1), 50-62.
} 
Indonesia sebagai negara penganut prinsip negara hukum atau rechtstaat sesungguhnya telah mengakomodir HAM bagi rakyatnya secara konstitusional, Indonesia berdasarkan UUD NRI 1945 menyatakan bahwa seluruh warga negara diberikan jaminan oleh negara untuk hidup tanpa ada diskriminasi dan memiliki hak untuk mendapatkan perlindungan sikap atau perlakuan yang diskriminatif. ${ }^{2} \mathrm{Hal}$ tersebut termaktub dalam Pasal 28 I UUD NRI Tahun 1945. Universal Declaration of Human Rights atau UDHR mengkehendaki bahwasanya segenap penduduk dunia berhak untuk hidup bebas dan memiliki hak yang setara antara individu satu dengan yang lainnya. ${ }^{3}$

Selain menganut prinsip negara hukum (rechtstaat) Indonesia juga menganut prinsip negara kesejahteraan atau walfare state, prinsip dari walfare state adalah bahwa negara bertanggung jawab atas kesejahteraan segenap warga negara tanpa ada pengecualian. ${ }^{4}$

Indonesia mengatur hak-hak disabilitas berdasarkan pada aturan-aturan yang tercantum pada UU Nomor 8 Tahun 2016 tentang Penyandang Disabilitas, hak-hak bagi para difabel dikelompokkan menjadi 3 (tiga) kategori yaitu : hak bagi penyandang disabilitas, hak yang diberikan khusus pada perempuan disabilitas serta hak untuk anak disabilitas, berdasarkan ketentuan yang ada dalam UU Penyandang Disabilitas terdapat beberapa hak, hak-hak tersebut antara lain kaum difabel memiliki kebebasan untuk hidup, hak untuk terbebas dari pencemaran nama baik, kaum difabel berhak atas privasi, berhak atas keadilan serta berhak atas perlindungan hukum, kaum difabel juga berhak atas pendidikan yang layak, berhak atas pekerjaan yang layak, kewirausahaan dan koperasi, kaum difabel juga berhak untuk hidup sehat, berhak untuk berpolitik, berhak untuk beragama, berhak untuk berolahraga, berhak untuk berpartisipasi dalam kebudayaan dan pariwisata, berhak atas kesejahteraan sosial, berhak atas akses, berhak atas pelayanan public, berhak untuk mendapatkan fasilitas untuk habilitasi dan rehabilitasi, kaum difabel berhak pula atas konsesi, berhak atas pendataan, berhak untuk hidup secara mandiri dan berhak untuk berperan dalam kegiatan dalam masyarakat, berhak untuk berekspresi dan berhak untu memperoleh informasi, berhak untuk berpindah tempat serta alih status kewarganegaraan, hak untuk bebas dari perlakuan pembedaan, pengabaian, penganiayaan, serta pemanfaatan seseorang secara berlebihan.

Tidak hanya hak-hak yang diberikan secara universal, UU Penyandang Disabilitas pula mengendalikan hak untuk wanita disabilitas, terdapat 4 ( empat) hak yang secara khusus diberikan untuk wanita disabilitas, hak tersebut ialah: hak atas kesehatan reproduksi, hak untuk menolak ataupun menerima pemakaian perlengkapan kontrasepsi, hak untuk memperoleh proteksi lebih dari perlakuan yang berbeda secara berlapis, berhak memperoleh proteksi lebih dari tindak kekerasan serta eskploitasi.

Mengenai hak bagi anak dengan disabilitas, terdapat 7 (tujuh) hak anak disabilitas, yaitu : anak difabel berhak untuk memperoleh perlindungan yang bersifat ekstra dari perlakuan yang berbeda, berhak untuk terbebas dari tindakan penelantaran,

2 Pranantha, I. K. I., \& Utari, A. A. S. (2016). Kewenangan Pemerintah Provinsi Bali Terhadap Perlindungan Disabilitas. Jurnal Kertha Negara, 4(05).

3 Yusa, I. G., \& Dharmawan, N. K. S. (2018). The Balinese Traditional Law Instrument: a Realism between the Balance of Cosmic and Human Rights Context. Padjadjaran Journal of Law, 5(3), 447-463.

${ }^{4}$ Hardjanti, D.K. (2016). Kajian Yuridis Penyandang Disabilitas. Perspektif Hukum, 16(1), 1-17. 
pelecehan, kekerasan dan eksploitasi organ intim, hak untuk mendapatkan penjagaan dan pengampuan dari keluarga atau keluarga wali untuk dapat berkembang dengan normal, anak difabel juga berhak untuk diakomodir kebutuhannya dalam pengambilan keputusan, berhak untuk mendapatkan tindakan yang manusiawi sesuai dengan hsrkat, martabat serta hak anak, berhak atas terpenuhinya kebutuhan khusus secara memadai, berhak atas perlakuan yang sama dengan anak-anak lain untuk mewujudkan keserasian sosial dan perkembangan individu, serta berhak untuk mendapatkan pendampingan dalam masyarakat. 5

Secara internasional hak asasi manusia sangat diperhatikan, hal ini dibuktikan dengan diadopsinya dua instrumen HAM yang utama yang terdiri dari Kovenan Internasional tentang Hak Ekonomi, Sosial dan Budaya serta Hak Sipil dan Politik. Sebagai instrumen hukum, kedua perjanjian tersebut memiliki nilai-nilai hukum serta normanorma yang bersifat universal. ${ }^{6}$ Meskipun masih ada negara di dunia yang hingga sekarang belum dapat melaksanakan ketentuan-ketentuan yang ada dalam Kovenan HAM Ekososbud dengan baik walaupun sudah meratifikasi kovenan tersebut. ${ }^{7}$

Menurut Komite HAM Ekososbud melalui General Comment Number 5 menyatakan bahwa penyandang disabilitas harus terbebas dari segala bentuk diskriminasi agar para penyandang disabilitas bisa hidup mandiri dan bedaulat. ${ }^{8}$

Penyandang disabilitas di Indonesia secara keseluruhan berjumlah 22 juta orang, hal ini terungkap dalam data sensus tahun 2015, data sensus juga mengungkapkan bahwa penyandang disabilitas di Indonesia lebih rentan mengalami kemiskinan, selain itu penyandang disabilitas di Indonesia juga masih sulit mengakses pendidikan, pekerjaan serta partisipasi dalam kegiatan sosial dan budaya. ${ }^{9}$

Di Indonesia terdapat sekitar 3,5 juta penyandang disabilitas netra ${ }^{10}$ yang menjadikan Indonesia sebagai negara nomor dua tertinggi di dunia dalam hal penduduk dengan keterbatasan pengelihatan. ${ }^{11}$ Sementara itu, berdasarkan data yang diperoleh dari world blind union menyatakan bahwa buku yang dicetak di seluruh negara yang ada di

${ }^{5}$ Purnomosidi, A. (2017). Konsep Perlindungan Hak Konstitusional Penyandang Disabilitas di Indonesia. Refleksi Hukum: Jurnal Ilmu Hukum, 1 (2), 161-174.

6 Smith, Rhona K.M ,dkk, (2013) , Hukum Hak Asasi Manusia, PUSHAM UII, Yogyakarta, h.18.

${ }^{7}$ Jaichan, Vinodh, (2010), An Introduction To International Human Rights Law edited by Azizur Rahman Chowdhury \& Jahid Hossain Bhuiyan, Koninklijke Brill NV, Leiden, The Netherland, h.52.

8 Pawestri, A. (2017). Hak Penyandang Disabilitas dalam Perspektif HAM Internasional dan HAM Nasional. Era Hukum-Jurnal Ilmiah Ilmu Hukum, 15(1).

9 https://www.bps.go.id/publication/2015/11/30/41ccbadf0b914534f5c08a62/pendudukindonesia-hasil-supas-2015.html

10 Presentation by Amannullah, G, Director of People Welfare Statistics, BPS - Statistics Indonesia. (2016). Measuring disability in Indonesia. https://unstats.un.org/unsd/demographic-social/meetings/2016/bangkok--disabilitymeasurement-and-statistics/Session-6/Indonesia.pdf

${ }^{11}$ Habsyiyah, H., Lestari, Y. D., Ariawan, I., \& Gondhowiardjo, T. D. (2015). Relationship of socioeconomic factors with vision-related quality of life on severe low vision and blind population in Indonesia. Medical Journal of Indonesia, 24(4), 245-51. 
dunia, selanjutnya dibuat dalam format lain yang dapat dengan mudah diakses oleh penyandang disabilitas netra sangat rendah, yaitu kurang dari $1 \% .12$

Hal tersebut tentu bertentangan dengan semangat CRPD yang mendukung penuh terciptanya kesetaraan antara kaum difabel dengan orang-orang yang normal. Adapun beberapa hambatan yang menyebabkan orang kesulitan dalam membaca buku cetakan adalah disebabkan oleh fungsi pengelihatan yang menurun, kebutaan permanen, menderita autisme atau menderita penyakit Parkinson serta kelumpuhan, dengan demikian maka diperlukan adanya media dengan format lain seperti buku audio atau audiobook.

Audiobook merupakan sarana yang dapat digunakan untuk membantu penyandang disabilitas netra dalam memenuhi kebutuhan buku bagi penyandang disabilitas netra. Adapun pengertian audiobook adalah sebuah buku yang dibaca dan direkam melalui CD atau format digital lainnya. ${ }^{13}$ Pengesahan persetujuan CRPD oleh Indonesia pada Tahun 2011 silam, serta penandatanganan Traktat Marrakesh yang disetujui di Marrakesh pada tahun 2013 yang ketentuan-ketentuannya merujuk kepada ketentuan yang ada dalam CRPD di antaramya adalah mengenai hak atas akses terhadap informasi, hak dalam kebebasan berekspresi, hak untuk memperoleh pendidikan yang layak, hak untuk berpartisipasi dalam kegiatan budaya, serta disahkannya UU yang mengakomodir kaum disabilitas pada Tahun 2016 diperkuat dengan ketentuanketentuan hukum yang mengatur tentang Kekayaan Intelektual (selanjutnya disebut KI) agar tidak menjadi hambatan bagi penyandang disabilitas untuk mendapatkan akses.

Hal tersebut memperlihatkan bahwa Indonesia memiliki komitmen yang kuat dalam melindungi hak-hak dasar serta meningkatkan kualitas hidup dari warga negara yang menjadi penyandang disabilitas.

Hak atas benda yang tidak berbentuk atau biasa dikatakan sebagai hak kekayaan intelektual, merupakan hak milik perseorangan, kekayaan intelektual jika diartikan secara sempit sebagai property rights, maka dapat digolongkan sebagai suatu HAM. ${ }^{14}$ Di Indonesia kini HKI dikenal dengan sebutan Kekayaan Intelektual atau KI saja, KI ialah suatu hasil dari olah pikir manusia untuk menunjang kesejahteraan hidup manusia itu sendiri. ${ }^{15}$ Istilah HKI dihapuskan sebab ingin menyeragamkan istilah yang saat ini digunakan oleh negara-negara lain di dunia. ${ }^{16}$ Hak Cipta merupakan salah satu bagian dalam $\mathrm{KI}$, hak cipta diatur dalam skala internasional maupun dalam skala

12 World Blind Union (2013). Press Release WIPO Negotiations Treaty for Blind people. Available at http://www.worldblindunion.org/english/news/pages/press-release-wiponegotiations-treaty-for-blind-people.aspx

13 Handayani, M. R. (2016). AUDIOBOOK SEBAGAI ALAT BANTU MEMPERLANCAR KOMUNIKASI DALAM PENYEBARAN DAKWAH ISLAM PENYANDANG TUNANETRA. Islamic Communication Journal, 1(1).

14 Supasti, N. K. (2014). Relevansi Hak Kekayaan Intelektual Dengan Hak Asasi Manusia Generasi Kedua. Jurnal Dinamika Hukum, 14(3), 518-527.

${ }^{15}$ Dewi, A. A. M. S. (2017). PERLINDUNGAN HUKUM HAK CIPTA TERHADAP COVER VERSION LAGU DI YOUTUBE. Jurnal Magister Hukum Udayana (Udayana Master Law Journal), 6(4), 508-520.

${ }^{16}$ Dharmawan, N.K.S. dkk. (2018). Harmonisasi Hukum Kekayaan Intelektual Indonesia, Swasta Nulus, Denpasar, h.3 
local. ${ }^{17}$ Hak Cipta diatur pada Pasal 1 hingga Pasal 14 TRIPs, yang menentukan bahwa perlindungan atas Hak Cipta mengacu pada ketentuan Berne Convention. UU Hak Cipta atau UUHC terbaru di Indonesia disahkan pada Tahun 2014 yang lalu, menggantikan UU Hak Cipta lama yang dibuat Tahun 2002. Ilmu pengetahuan, seni, serta karya sastra merupakan obyek yang diberikan proteksi oleh hak cipta. ${ }^{18}$

Berdasarkan pemaparan awal diatas dapat diketahui bahwa akses terhadap suatu karya cipta, terutama buku elektronik bagi penyandang disabilitas netra sangat terbatas sehingga hak-hak dari penyandang disabilitas netra terhadap suatu karya cipta menjadi terabaikan sehingga perlu dilindungi secara hukum agar hak-hak penyandang disabilitas netra atas suatu karya cipta dapat terpenuhi. Karena pentingnya perlindungan hukum terhadap akses karya cipta khususnya buku elektronik bagi penyandang disabilitas netra, maka hal tersebut sangat menarik untuk dijadikan karya ilmiah berupa jurnal hukum dengan judul "Akses Karya Cipta Audiobook Bagi Disabilitas Netra : Perspektif HAM"

Adapun rumusan masalah dari penelitian ini yaitu bagaimanakah pengaturan perlindungan hukum akses karya cipta audiobook bagi penyandang disabilitas netra dalam Traktat Marrakesh ?, dan bagaimanakah perlindungan hukum akses karya cipta audiobook bagi penyandang disabilitas netra di Indonesia ?. Tujuan dari dilaksanakannya penelitian ini adalah mengingat bahwa kesetaraan hak antar individu tersebut sangatlah penting, sedangkan berdasarkan data awal yang telah dipaparkan di atas menunjukkan bahwa hak dari kaum disabilitas khususnya kaum difabel netra dalam mengakses karya cipta tidak dapat terpenuhi secara maksimal, oleh sebab itulah maka penelitian ini akan mengkaji lebih lanjut dari prespektif hukum serta HAM mengenai aturan hukum yang melindungi kaum difabel netra dalam mengakses ciptaan baik secara internasional maupun secara nasional.

Indonesia sebagai salah satu negara besar di dunia nampak abai dengan keberadaan kaum difabel, di Indonesia kaum difabel masih sulit mendapatkan akses terhadap pekerjaan yang layak, begitu pula dengan pendidikan, kaum difabel masih sulit mengakses kedua hal tersebut, setidaknya begitulah gambaran yang didapat dari hasil penelitian yang dilakukan oleh Jazim Hamidi pada Tahun 2016 yang lalu. ${ }^{19}$

Selain masalah pendidikan dan pekerjaan, keberpihakan hukum terhadap kaum difabel juga disorot, masih banyak kaum difabel yang tak berdaya dihadapan hukum, hal ini ditengarai disebabkan oleh kondisi ekonomi serta factor budaya dan rendahnya penegakan hukum yang memberikan keberpihakan kepada kaum difabel, hal ini diungkap oleh Rahayu Repindowati Harahap dalam penelitiannya yang dilakukan tahun 2015.20

17 Mahadewi, K. J. (2015). Budaya Hukum dalam Keberlakuan Undang-undang Nomor 28 Tahun 2014 Tentang Hak Cipta pada Pengrajin Perak di Bali. Jurnal Magister Hukum Udayana (Udayana Master Law Journal), 4(2).

${ }^{18}$ Dharmawan. N.K.S. dkk. op.cit. h.3.

19 Hamidi, J. (2016). Perlindungan Hukum terhadap Disabilitas dalam Memenuhi Hak Mendapatkan Pendidikan dan Pekerjaan. Jurnal Fakultas Hukum UII, 23(4), 652-671.

${ }^{20}$ Repindowaty, R. (2015). Perlindungan Hukum Terhadap Penyandang Disabilitas Menurut Convention on The Rights of Persons With Disabilities (CRPD). Inovatif: Jurnal Ilmu Hukum, 8(1). 


\section{Metode Penelitian}

Studi hukum ini menggunakan jenis pengkajian normatif dengan pendekatan perundang-undangan dan pendekatan komparatif, sebab, norma merupakan objek kajian dari ilmu hukum, norma hukum inilah yang selanjutnya digunakan sebagai dasar oleh masyarakat secara umum dalam bertindak, dapat dikatakan bahwa inti dari kajian normatif adalah penelitian terkait norma hukum yang berlaku di masyarakat.

\section{Hasil dan Pembahasan}

\subsection{Pengaturan Perlindungan Hukum Aksesibilitas Karya Cipta Bagi Disabilitas Netra dalam Traktat Marrakesh}

Dalam DUHAM, HAM disebut sebagai dasar bagi kemerdekaan, keadilan serta perdamaian dunia, dengan demikian, semua orang termasuk kaum difabel mempunyai hak yang setara serta tanpa diskriminasi. ${ }^{21}$ Sedangkan perlindungan terhadap harkat dan martabat serta hak-hak dasar dari subyek hukum dapat disetarakan dengan istilah perlindungan hukum. ${ }^{22}$

Adapun Traktat Marrakesh pada intinya merupakan traktat yang memberikan perlindungan hukum bagi penyandang disabilitas netra agar dapat mengakses karyakarya cipta terutama buku, Traktat Marrakesh merupakan kelanjutan dari DUHAM dan Konvensi tentang Hak-Hak Disabilitas. Lior Zemer dan Aviv Gaon dalam karya ilmiahnya menyatakan bahwa Traktat Marrakesh memiliki tujuan untuk mengatasi persoalan hukum terkait akses bagi penyandang disabilitas netra terhadap materi yang diberikan proteksi dengan hak cipta. ${ }^{23}$ Dalam Pasal 2 huruf a Traktat Marrakesh, diatur bahwa istilah karya yang dimaksud dalam perjanjian tersebut adalah karya sastra dan seni, dalam bentuk teks, notasi dan/atau ilustrasi istimewa, baik yang terpublikasi atau yang tersedia untuk umum di dalam media apapun, salah satunya dalam bentuk audio, seperti audiobook atau buku audio. Selanjutnya, Pasal 2 huruf b Traktat Marrakesh mengatur tentang format yang dapat diakses oleh penerima manfaat, Traktat Marrakesh mengizinkan format apa saja selama penerima manfaat dapat mengakses dengan layak dan senyaman orang tanpa gangguan pengelihatan dengan tetap memperhatikan hak moral dari pencipta kemudian pada Pasal 2 huruf c Traktat Marrakesh diatur bahwa yang dapat membuat salinan format adalah lembagalembaga yang diakui oleh pemerintah termasuk lembaga-lembaga atau organisasi nirlaba.

Traktat Marrakesh dalam Pasal 3 menentukan penerima manfaat adalah mereka yang memiliki gangguan pengelihatan yang mengakibatkan tidak dapat membaca bahan cetakan dengan efektif. Pasal 4 Traktat Marrakesh menentukan bahwa Jaminan fasilitasi akses bagi penyandang disabilitas netra diberikan dalam bentuk pembatasan

${ }^{21}$ Rompis, K.G. (2016). Perlindungan Hukum Terhadap Penyandang Disabilitas dalam Perspektif Hukum Hak Asasi Manusia. Lex Administratum, 4(2).

22 Putra. W., \& Wibowo, A. (2018). PELAKSANAAN PERLINDUNGAN HUKUM TERHADAP PERSAMAAN HAK BAGI KELOMPOK PENYANDANG DISABILITAS DALAM ANGKUTAN PENERBANGAN, Jurnal Hukum Adigama, 1(1).

${ }^{23}$ Zemer, L., \& Gaon, A. (2015). Copyright, disability and social inclusion: The Marrakesh Treaty and the role of non-signatories. Journal of Intellectual Property Law \& Practice, 10(11), 836-849. 
dan pengecualian dalam perundang-undangan yang terkait dengan hak cipta, batasan tersebut terkait dengan hak produksi dan hak distribusi serta hak untuk menyediakan kepada publik suatu karya cipta agar dapat diakses oleh penyandang disabilitas netra, sehingga kegiatan produksi dan distribusi maupun penyediaan suatu karya cipta untuk penyandang disabilitas netra nantinya tidak melanggar ketentuan perundangundangan terkait hak cipta.

Traktat Marralesh juga mengatur mengenai impor salinan format yang dapat diakses serta mewajibkan para pihak dalam perjanjian tersebut untuk memberikan perlindungan hukum kepada penyedia atau penerbit agar salinan format dari suatu karya cipta tidak diakses secara illegal tanpa mengurangi hak-hak dari penyandang disabilitas netra yang telah secara sah memiliki hak untuk mengakses karya cipta tersebut serta para pihak juga melindungi privasi penerima fasilitasi akses atas dasar kesetaraan dengan yang lainnya, hal ini diatur dalam Pasal 8 Traktat Marrakesh.

Berdasarkan uraian beberapa pasal dari Traktat Marrakesh, secara jelas dapat diketahui bahwa Traktat Marrakesh telah melindungi hak-hak penyandang disabilitas dalam memperoleh akses terhadap ilmu pengetahuan atau informasi khususnya dalam bentuk salinan digital dengan format apapun.

\subsection{Pengaturan Perlindungan Akses Karya Cipta Audiobook Bagi Penyandang Disabilitas Netra di Indonesia}

Di Indonesia HAM dapat dipersamakan dengan istilah hak kodrati, prinsip perlindungan terhadap HAM serta perlindungan hukum merupakan satu bagian yang tak terpisahkan. ${ }^{24}$

Menjadi penyandang disabilitas seharusnya bukanlah menjadi halangan yang berat untuk mendapatkan hak-hak dasar seperti berhak untuk hidup, berhak memperoleh layanan kesehatan yang layak, berhak untuk mendapatkan pendidikan yang layak maupun hak-hak dasar lainnya. ${ }^{25}$

Berdasarkan UU Penyandang Disabilitas pada Pasal 5 ditentukan bahwa memperoleh pendidikan serta informasi merupakan salah satu hak bagi kaum difabel, untuk mengoptimalkan pemberian hak pendidikan dan informasi bagi penyandang disabilitas maka diperlukan sarana-sarana penunjang seperti buku dengan huruf Braille, audiobook, buku elektronik, atau buku-buku serta sumber informasi lainnya yang dibuat dalam bentuk yang khusus, sehingga nantinya dapat diakses oleh kaum difabel, mengingat pada saat ini kemajuan dibidang teknologi sangatlah pesat, sehingga harapan para penyandang untuk dapat mengakses ilmu pengetahuan maupun informasi sangat terbuka.

Indonesia merupakan salah satu pihak yang ikut meratifikasi Traktat Marrakesh, dengan demikian maka Indonesia wajib untuk mengejawantahkan ketentuanketentuan yang termuat dalam perjanjian tersebut ke dalam aturan resmi yang diberlakukan di Indonesia.

${ }^{24}$ Aswandi, B. \& Roisah, K. (2019). NEGARA HUKUM DAN DEMOKRASI PANCASILA DALAM KAITANNYA DENGAN HAK ASASI MANUSIA (HAM). Jurnal Pembangunan Hukum Indonesia, 1 (1), 128-145.

${ }^{25}$ Hidayatullah, A.N. \& Pranowo, P. (2018). Membuka Ruang Asa dan Kesejahteraan Bagi Penyandang Disabilitas, Jurnal Penelitian Sosial, 17 (2), 195-206. 
Kekayaan Intelektual, khususnya Hak Cipta, UUHC yang berlaku di Indonesia sekarang ini telah mengakui keberadaan penyandang disabilitas, khususnya penyandang disabilitas netra, hal ini dapat diketahui dalam ketentuan pada Pasal 44 ayat (2) yang pada intinya menentukan bahwa penggunaan suatu karya cipta bagi kaum disabilitas netra dalam bentuk huruf braille atau audiobook dan format lainnya bukan merupakan suatu bentuk pelanggaran hak cipta, dengan syarat mencantumkan sumber secara lengkap dan tidak bersifat komersil.

UUHC 2014 pada intinya mengamanatkan adanya peraturan pemerintah yang mengatur mengenai fasilitasi akses terhadap ciptaan bagi penyandang disabiitas netra, berdasarkan ketentuan tersebutlah peraturan pemerintah yang mengakomodir akses ciptaan bagi kaum difabel disahkan pada 2019.

Secara umum Peraturan Pemerintah Nomor 27 Tahun 2019 tentang Fasilitasi Akses Terhadap Ciptaan Bagi Penyandang Disabilitas dalam Membaca dan Menggunakan Huruf Braille, Buku Audio dan Sarana Lainnya mengatur mengenai apa yang dimaksud dengan ciptaan dan fasilitasi akses, siapa saja yang berhak menjadi penerima manfaat fasilitasi akses serta penerima fasilitasi akses yang diatur pada Pasal 1 hingga Pasal 3, khusus mengenai penerima fasilitasi akses hanya diberikan pada perpustakaan yang memiliki fasilitas bagi penyandang disabilitas serta lembaga dan instansi pemerintah yang memiliki tugas memberikan fasilitas bagi penyandang disabilitas dan organisasi masyarakat atau organisasi sosial yang memiliki tujuan memfasilitasi penyandang disabilitas serta orang-perseorangan yang secara sukarela membantu penyandang disabilitas dengan syarat tidak bersifat komersial. Berkaitan dengan bentuk-bentuk fasilitasi akses yang diberikan diatur dalam Pasal 5 , fasilitasi akses yang diberikan tetap mengutamakan hak moral yang melekat pada pencipta, pemberian fasilitasi akses ini diatur tata cara pemberiannya merujuk pada ketentuan yang tercantum pada Pasal 7 hingga Pasal 10 serta Pasal 11 hingga Pasal 13 mengatur mengenai tata cara pemberian salinan digital.

Berdasarkan uraian diatas dapat diketahui bahwa Indonesia telah menjadikan Traktat Marrakesh sebagai rujukan dalam pembuatan aturan yang mengakomodir kebutuhan kaum difabel utamanya kaum difabel netra yang berlaku di Indonesia, dan ketentuan tersebut juga telah melindungi hak-hak kaum difabel, khususnya kaum difabel netra dalam memperoleh akses terhadap ilmu pengetahuan atau informasi.

\section{Kesimpulan}

Perlindungan hukum aksesibilitas karya cipta bagi penyandang disabilitas netra telah diatur secara jelas dalam Traktat Marrakesh. Traktat Marrakesh menjamin fasilitasi akses terhadap karya cipta bagi penyandang disabilitas netra melalui pembatasan dan pengecualian hak cipta bagi negara-negara yang meratifikasi Traktat Marrakesh, serta melindungi privasi penerima manfaat.

Perlindungan hukum aksesibilitas karya cipta audiobook di Indonesia telah diatur berdasarkan Peraturan Pemerintah Nomor 27 Tahun 2019 Tentang Fasilitasi Akses Terhadap Ciptaan Bagi Penyandang Disabilitas dalam Membaca dan Menggunakan Huruf Braille, Buku Audio dan Sarana Lainnya yang merupakan amanat dari ketentuan Pasal 44 ayat (4) UUHC 2014. 


\section{Daftar Pustaka}

\section{Buku}

Dharmawan, N.K.S. dkk. (2018), Harmonisasi Hukum Kekayaan Intelektual Indonesia, Swasta Nulus.

Smith K.M, Rhona. dkk. (2013), Hukum Hak Asasi Manusia, PUSHAM UII.

Jaichan, Vinodh. (2010), An Introduction To International Human Rights Law edited by Azizur Rahman Chowdhury \& Jahid Hossain Bhuiyan, Koninklijke Brill NV, Leiden, The Netherland

\section{Jurnal}

Aswandi, B. \& Roisah, K. (2019). NEGARA HUKUM DAN DEMOKRASI PANCASILA DALAM KAITANNYA DENGAN HAK ASASI MANUSIA (HAM). Jurnal Pembangunan Hukum Indonesia, 1 (1), 128-145.

Dewi, A. A. I. A. A. (2018). Aspek Yuridis Perlindungan Hukum dan Pemenuhan Hak Penyandang Disabilitas. Pandecta: Research Law Journal, 13(1), 50-62.

Dewi, A. A. M. S. (2017). PERLINDUNGAN HUKUM HAK CIPTA TERHADAP COVER VERSION LAGU DI YOUTUBE. Jurnal Magister Hukum Udayana (Udayana Master Law Journal), 6(4), 508-520.

Habsyiyah, H., Lestari, Y. D., Ariawan, I., \& Gondhowiardjo, T. D. (2015). Relationship of socioeconomic factors with vision-related quality of life on severe low vision and blind population in Indonesia. Medical Journal of Indonesia, 24(4), 245-51.

Hamidi, J. (2016). Perlindungan Hukum terhadap Disabilitas dalam Memenuhi Hak Mendapatkan Pendidikan dan Pekerjaan. Jurnal Fakultas Hukum UII, 23(4), 652671.

Handayani, M. R. (2016). AUDIOBOOK SEBAGAI ALAT BANTU MEMPERLANCAR KOMUNIKASI DALAM PENYEBARAN DAKWAH ISLAM PENYANDANG TUNANETRA. Islamic Communication Journal, 1(1).

Hardjanti, D.K. (2016). Kajian Yuridis Penyandang Disabilitas. Perspektif Hukum, 16(1), $1-17$.

Hidayatullah, A.N. \& Pranowo, P. (2018). Membuka Ruang Asa dan Kesejahteraan Bagi Penyandang Disabilitas, Jurnal Penelitian Sosial, 17 (2), 195-206.

Mahadewi, K. J. (2015). Budaya Hukum dalam Keberlakuan Undang-undang Nomor 28 Tahun 2014 Tentang Hak Cipta pada Pengrajin Perak di Bali. Jurnal Magister Hukum Udayana (Udayana Master Law Journal), 4(2).

Pawestri, A. (2017). Hak Penyandang Disabilitas dalam Perspektif HAM Internasional dan HAM Nasional. Era Hukum-Jurnal Ilmiah Ilmu Hukum, 15(1).

Pranantha, I. K. I., \& Utari, A. A. S. (2016). Kewenangan Pemerintah Provinsi Bali Terhadap Perlindungan Disabilitas. Jurnal Kertha Negara, 4(05).

Purnomosidi, A. (2017). Konsep Perlindungan Hak Konstitusional Penyandang Disabilitas di Indonesia. Refleksi Hukum: Jurnal Ilmu Hukum, 1 (2), 161-174.

Putra. W., \& Wibowo, A. (2018). PELAKSANAAN PERLINDUNGAN HUKUM TERHADAP PERSAMAAN HAK BAGI KELOMPOK PENYANDANG DISABILITAS DALAM ANGKUTAN PENERBANGAN, Jurnal Hukum Adigama, $1(1)$.

Repindowaty, R. (2015). Perlindungan Hukum Terhadap Penyandang Disabilitas Menurut Convention on The Rights of Persons With Disabilities (CRPD). Inovatif: Jurnal Ilmu Hukum, 8(1).

Rompis, K. G. (2016). Perlindungan Hukum Terhadap Penyandang Disabilitas dalam Perspektif Hukum Hak Asasi Manusia. Lex Administratum, 4(2). 
Supasti, N. K. (2014). Relevansi Hak Kekayaan Intelektual Dengan Hak Asasi Manusia Generasi Kedua. Jurnal Dinamika Hukum, 14(3), 518-527.

Yusa, I. G., \& Dharmawan, N. K. S. (2018). The Balinese Traditional Law Instrument: a Realism between the Balance of Cosmic and Human Rights Context. Padjadjaran Journal of Law, 5(3), 447-463.

Zemer, L., \& Gaon, A. (2015). Copyright, disability and social inclusion: The Marrakesh Treaty and the role of non-signatories. Journal of Intellectual Property Law $\mathcal{E}$ Practice, 10(11), 836-849.

Internet

Badan Pusat Statistik. (2015). Survei Penduduk Antar Sensus (SUPAS). https://www.bps.go.id/publication/2015/11/30/41ccbadf0b914534f5c08a62/ penduduk-indonesia-hasil-supas-2015.html

Presentation by Amannullah, G, Director of People Welfare Statistics, BPS - Statistics Indonesia. (2016). Measuring disability in Indonesia. https://unstats.un.org/unsd/demographicsocial/meetings/2016/bangkok-disability-measurement-and-statistics/Session-6/Indonesia.pdf.

World Blind Union (2013). Press Release WIPO Negotiations Treaty for Blind people http://www.worldblindunion.org/english/news/pages/press-release-wiponegotiations-treaty-for-blind-people.aspx.

\section{Peraturan Perundang-Undangan}

Undang-Undang Dasar Negara Republik Indonesia Tahun 1945.

Undang-Undang Nomor 28 Tahun 2014 Tentang Hak Cipta

Undang-Undang Nomor 8 Tahun 2016 Tentang Penyandang Disabilitas

Peraturan Pemerintah Nomor 27 Tahun 2019 Tentang Fasilitasi Akses Terhadap Ciptaan Bagi Penyandang Disabilitas dalam Membaca dan Menggunakan Huruf Braille, Buku Audio dan Sarana Lainnya.

Convention On The Rights Of Person with Disabilities (CRPD)

Marrakesh Treaty To Facilitate Access To Published Works by Visually Impaired Persons and Person With Print Disabilities. 